\title{
You, Too, Will Speak English Soon: The Pros and Cons of English as a Business Lingua Franca
}

\author{
Heiko Wiggers ${ }^{1}$ \\ ${ }^{1}$ Wake Forest University, Winston-Salem, NC, USA \\ Correspondence: Heiko Wiggers, Department of German and Russian, Wake Forest University, P.O. Box 7353, \\ Winston-Salem, NC 27109, USA. Email: wiggerh@wfu.edu
}

Received: May 8, 2018; Accepted: June 2, 2018; Published: June 15, 2018

\begin{abstract}
This paper discusses the increasing use of English as a Business Lingua Franca (BELF). In particular, this paper examines case studies from several companies located in diverse countries (Japan, Germany, and Finland), where English has been implemented as an internal lingua franca. The case studies show that most employees at these companies adjusted to BELF in a very pragmatic manner, while others considered the employment of BELF to be an intrusive course of action. This paper also investigates how BELF is viewed by native speakers of English and argues that attitudes towards foreign language learning by native speakers of English may constitute an impediment to efficient communication between speakers of different native languages and backgrounds. Finally, this papers shows that the acceptance of BELF, at least to a certain degree, is dependent on attitudes towards the global spread of English.
\end{abstract}

Keywords: Global English, lingua franca, language attitudes, language as commodity

\section{Introduction I: Oettinger's Blunder}

The Verein Deutsche Sprache (German Language Society), founded in 1997, is an association whose primary goal is "to preserve and promote the German language as an independent cultural entity". (Note 1) One of its main objectives is to stem the increasingly strong influx of English or pseudo-English vocabulary words and other features of English into the German language (also known as "Denglisch", i.e. a blend of the words Deutsch and Englisch). Once a year, in a highly publicized event, the society bestows an award upon a public figure or public organization in Germany for "particularly noteworthy blunders in dealing with the German language." Typically, the public figure or organization in question is found "guilty" by the society of excessively mixing German and English, hence the award's name Sprachpanscher des Jahres ("language mixer of the year"). In 2006 this dubious honor was conferred on Günther Oettinger, then governor (Ministerpräsident) of the federal state of BadenWürtemberg. His offense? In a television interview in 2006 Oettinger suggested that the primary language in German companies and businesses should be English, and that German should be used with friends and family outside of work.

\section{Introduction II: English as a Lingua Franca}

More than ten years later Oettinger's vision has not (yet) become a reality in German-speaking countries. His "blunder", though, demonstrates how important and in demand the English language has become in the last decades. In fact, the nearly world-wide trend of English becoming a lingua franca in Business and other sectors of public life has gained greater traction in the new millennium than ever before. It is often argued that the need for a global language has never been more crucial than now, particularly if one considers the significance of modern communications, globalized trade, and easy international travel in our modern "global village". Since ancient times language barriers between potential trading partners have adversely affected international trade, a problem that has continued into modern times. (Note 2) Ku and Zussman (2010), for example, point out that a large body of studies "find robust evidence that a language barrier reduces trade." (2010, 250). Similarly, Lohmann (2010) adds that not understanding each other's languages can be one of the most significant obstacles in bilateral trade relationships:

"Language barriers may be more important to international trade than previously thought, [and] language barriers are significantly negatively correlated with bilateral trade." $(2010,159)$

While it is obviously commendable to learn the language of one's trading partner, the process of doing so can be very arduous and costly. In addition, such an undertaking can be risky and uncertain in case the business 
relationship ends, or one finds a new trading partner who speaks a different native language. The situation becomes even more complex if more than two trading partners with different native languages engage in trade with each other. It might therefore be more advantageous that trading partners communicate with each other via a language that is non-native to both or all of them. Crystal (2003) lists several scenarios in which a lingua franca would be much more practical than learning the specific language of one's business partner, conference partner, or fellow scientist:

"A conversation over the Internet between academic physicists in Sweden, Italy, and India is at present practicable only if a common language is available. A situation where a Japanese company director arranges to meet German and Saudi Arabian contacts in a Singapore hotel to plan a multi-national deal would not be impossible, if each plugged in to a 3-way translation support system, but it would be far more complicated than the alternative, which is for each to make use of the same language." $(2003,13)$

The language in question here is, of course, English. It must be pointed out, though, that throughout the centuries various other languages have been used as lingua francas. Latin, for example, was utilized if not spoken in the whole of the Roman Empire for a long time. Likewise, Arabic, French, Greek, Spanish, and Swahili have all served or still serve at one time or another as lingua francas. Choosing or accepting a lingua franca is often determined by internal or external factors, which in turn largely determine whether the lingua franca is an indigenous or an imported language. Internal factors, such as being the most powerful ethnic group in a particular area, can aid an indigenous language to emerge as a lingua franca, for example Mandarin Chinese (Crystal: 2003, 11). Other internal factors, such as favorable geographical locations or clever business practices can even turn languages that are considered dialects, variations, or creoles of standard languages into highly regarded lingua francas. Low German, for instance, a West-Germanic language that was once widely spoken in northern Germany and is now considered an endangered dialect, was the lingua franca of the mighty Hanseatic League, a confederation of merchants that dominated the maritime trade in northern Europe for several centuries. (Note 3) Likewise, West African Pidgin English, a hybrid language based on Pidgin English and local African languages, is to this day widely used as a lingua franca between various ethnic groups along the West African coast. Usually, however, external factors play a more crucial role in choosing or accepting a lingua franca, as Crystal mentions:

"Most often, a language is accepted from outside the community, such as English or French, because of the political, economic, and religious influence of a foreign power." $(2003,11)$

Indeed, the example of Latin as the first or at least one of the first documented lingua francas demonstrates that "hard power" rather than "soft power" is a much more compelling argument in choosing (or being forced to accept) a lingua franca than, say, the literature or culture of a particular language:

"Ease of learning has nothing to do with it. [...] A language does not become a global language because of its intrinsic structural properties, or because of the size of its vocabulary, or because it has been a vehicle of great literature in the past, or because it was once associated with a great culture or religion. [...] A language has traditionally become an international language for one chief reason: the power of its people - especially their political and military power." (Crystal, 2003, 8-9). (Note 4)

The rise of English to a global language has been extensively discussed and documented (McCrum, Macneil \& Cran, 2002; Bragg, 2011) and need not be detailed here further. It should be added, though, that the spread of English has its roots in a curious combination of soft power and hard power, which were and are employed by its two most prominent proponents, the UK and the U.S. While the UK used primarily hard power (colonialism, empire building, suppression of indigenous languages; all of which were originally also applied to their North American colonies), the U.S. used mainly soft power (economic strength, its entertainment industry, music, etc.), which at times even included humanitarian missions, e.g. the Marshall Plan to rebuild post-W.W. II Europe, or its past and present role to help fight the global AIDS epidemic. (Note 5) In fact, considering that the United States is largely a nation comprised of immigrants, one could even question whether the spread of English, at least initially, was not an unintended by-product of the country's influence in the world. It should be noted that the rise of the United States to a global power coincided with the birth of popular computing. New technological inventions and devices, such as personal computers, the Internet, and more recently smart phones, all had their origin in the U.S., and their subsequent worldwide use greatly advanced the global spread of English.

Throughout the $20^{\text {th }}$ century English rapidly spread to establish itself as one of the most spoken languages in the world. While the number of native English speakers in the world (approximately three hundred and sixty million) might pale in comparison to ca. 1.2 billion native speakers of Chinese, it is the vast number of people who speak English as a second language (ca. 500 million) and millions of pupils and students around the world who learn the language in schools that make English a truly international language and today's most used lingua franca. 
The use of English as a Lingua Franca (ELF), and more recently the introduction of BELF (English as Business Lingua Franca/Business English as Lingua Franca) has become a much discussed topic since the beginning of the new millennium among language teachers, applied linguists, and economists alike (Trudgill \& Hannah, 2002; Jenkins, 2007; Seidlhofer, 2011). Much of the discussion focuses on the fact that any lingua franca is "far removed from its native speakers' linguacultural norms and identities." (Seidlhofer, 2001) In other words, the number of speakers who use English as a lingua franca has not only substantially increased in the new millennium but their English or variations thereof also tend to be different than those of native speakers. Linguistically speaking, new variations of a common language are nothing new; most Romance languages are, after all, descendants of Latin. With regards to the use of English as a lingua franca, Louhiala-Salminen and Kankaanranta (2012) comment that "the very concept of ELF entails that it is used by speakers of different mother tongues." $(2012,264)$ In addition, a lingua franca is usually not part of its speakers' identity and mostly just a means to an end. This in turn has led to discussions about the universal ownership of English, whose English should be the basis of ELF or BELF, and also how "correct" ELF/BELF has to be, as Seidlhofer (2001) points out:

"The "problems" which Danes, Catalans, etc. have with English may be problems in the eye of the native speaker beholder [...]. But "English" does not simply transfer intact from one context to another - the 'E' in English as a Native Language is bound to be something very different from the 'E' in English as a Lingua Franca, and must be acknowledged as such." (2001, 137-138)

Although the discussion is ongoing, most scholars agree that ELF is culturally neutral:

"ELF, unlike major national standards of English, is not used for expressing one's national or ethnic identity." (Smokotin, Alekseyenko \& Petrova; 2014, 511)

The above-mentioned authors also point out that any deviations of ELF from Standard English in terms of grammar, lexicon, and phonetics "spring from the functional roles of ELF $[\ldots]$ of connecting people with different linguistic and ethnic backgrounds." (2014, 511).

\section{Methodology I: English as an Internal Lingua Franca - A Case Study from Japan}

A relatively new component to this discussion is the use of English as an internal means of communication in business, i.e. English is made the internal working language of a company regardless of its geographical location (and thus making Oettinger's suggestion from the beginning of this article a reality). Such an arrangement would obviously make little sense for a medium-sized carpentry with thirty employees in France, a family-owned restaurant in Italy, or a hairdresser's shop in Germany. It does make sense, however, for a multinational corporation with subsidies in many different countries. These are often companies that originated in the UK or the U.S., and whose business languages were thus English to begin with. But this trend is not limited to Anglo-American corporations. One of the most cited cases in this regard is Japan's largest e-commerce retailer, Rakuten. On the morning of March 1, 2010, Rakuten's CEO, Hiroshi Mikitani, announced to his workforce an English-only mandate in his company:

"Our goal is to catch up with the global market. To step up to this challenge we must try to change our language gradually from Japanese to English. This is going to be a long-term effort for us. Starting this month, my own speech will simply be in English."

(Neeley: 2017, 14)

By the next morning, all Japanese menus in the company's cafeterias were replaced with English ones, and all floor directories were in English as well. In addition, all meetings, presentations, documents, training sessions, and emails were to be conducted entirely in English. Mikitani's mandate caused international headlines and triggered emotional reactions inside and outside his company. Fellow CEO Takanobu Ito from Honda Motors, for instance, criticized the new language policy sharply: "It's stupid for a Japanese company to only use English in Japan when the workforce is mainly Japanese." (Neeley: 2017, 20) Mikitani's seemingly radical action was prompted by the realization that his company would never be able to successfully compete with other e-retailers, if it did not become more international:

"Of course, in this day and age, the pressure is on. If Rakuten is going to continue expanding and competing against rivals like Amazon and Alibaba, then English is an absolute necessity. Without the ability to quickly respond in English by email, in meetings, or during presentations, no company can succeed globally."

(The Japan Times, March 23, 2015) 
It needs to be said that Mikitani's transformation of Rakuten's corporate policies, and indeed its corporate culture, did not result in firings or a high turnover in Rakuten's workforce. Instead of hiring new employees who speak English, Mikitani used a soft approach by deciding to retain his present staff and bringing in elite teams of English instructors. Several years later it seems that Mikitani's gamble had paid off. Commercially, Rakuten was able to expand more on the international market and even acquired stakes in Pinterest. Most of its employees now have a passable command of English with an average score of 800 on the TOEIC (Test of English for International Communication), an exam that has become mandatory at Rakuten and that employees need to take regularly to demonstrate progress in English.

Still, Rakuten's lingua franca adoption created a paradigm shift that had significant consequences for its employees. Neeley (2017), who researched the venture extensively, reports that the company's "Englishnization" created resentment and frustration among its staff. Many native Japanese employees reported a self-perceived loss in status due to the new English mandate, especially when they were compared to other Asian colleagues from Thailand, Taiwan, and Indonesia who were more familiar with the English language (2017, 50). According to Neeley, a Tokyo developer who was employed with Rakuten commented:

"Employees who cannot speak English are feeling inferior. At meetings, they cannot articulate their opinions. I have seen opinions accepted just because they were couched in good English, not because the content of the opinion was great." $(2017,51)$

In addition, many employees had feelings of anxiety when the project first began and were worried about their job security. Neeley reports that these concerns only started to recede after approximately two years when employees "met or exceeded the proficiency guidelines" $(2017,53)$, but that they never completely went away. Surprisingly, the intense language training and resulting increased proficiency scores came with a new set of problems that were rather unexpected:

“Ultimately, the [employees'] efforts yielded partial language skills but were too narrow to produce advanced skills. [...] They acquired some degree of fluency, but it was insufficient to enable automaticity of the kind that native speakers develop. No matter how much they improved, they never achieved the natural ease of their fluent native language. They were not able to relegate their lingua franca learning into the background. It remained an effortful foreground struggle." (Neeley: 2017, 55)

Since Neeley does not offer any comments, it remains unclear as to why the majority of Rakuten's employees were unable to achieve near-native fluency in English. It is possible that the reasons can be found in Japan's unique geographic, historical, and linguistic situation. (Note 6) Culturally speaking, it might also be conceivable that the aforementioned perceived loss of status was associated by the employees with a "loss of face" and thus caused them to feel resentment toward mastering the English language. As Neeley explains in a different article:

"When nonnative speakers are forced to communicate in English, they can feel that their worth to the company has been diminished." $(2012,58)$

Whatever the reasons were, Rakuten's mandated lingua franca constitutes an interesting and perhaps unique case study, both in economic and linguistic terms, since the main purpose of Mikitani's experiment was to become more global. In a European context, foreign language requirements are somewhat ubiquitous for employment in larger corporations; and while promoting English as an internal lingua franca is not unheard of, it usually occurs after a company has become more international. The following section examines three case studies from Europe where English was made either an internal working language or was extensively adopted for professional purposes.

\section{Methodology II: Case Studies from Europe}

The first case study concerns a family-owned, multinational company in the technology sector from Germany. Ehrenreich, the study's author, gives the company the acronym TechComp (not its real name), and reports that "over the past 20 years, TechComp has gradually but steadily developed from a national medium-sized enterprise into a highly globalized corporation" (2010: 416), and is still headquartered in Germany. After becoming highly international and global, the company decided to adopt English as an internal working language in the early 2000s; however, unlike Rakuten, the top management never officially issued a mandate to use English only, as Ehrenreich points out:

"Although English is not officially the corporate language at TechComp, its status as the de facto lingua franca of international business is undisputed. There is unanimous agreement [...] that English is a "must" for managers and employees in all locations and at practically all levels, all the way from top management down to regular office workers and, most importantly, secretaries in top and middle management. [...] 
English is no longer an asset on CVs but has turned into a sine qua non, which means that job candidates without English will basically not be hired. $(2010,417)$

The focal point of Ehrenreich's study was to find out how the adoption of BELF at TechComp had affected its employees, particularly those in upper management, and how they adjusted to speaking primarily English on the job. She observed that almost everyone at the company had a very pragmatic view with regards to speaking English. Nobody felt that English was imposed on them; instead is was largely seen as "a fact of life" $(2010,420)$, an additional job requirement that could be mastered with sufficient practice. As manager "D" points out:

"It's like... well, we're all swimming in water, and you either sink or swim. "No English" is not an option. English is a means to an end. For me, English is not an end in itself." (Ehrenreich, 2010, 417)

Manager "B" explained how much s/he appreciated English as a facilitator in interactions with foreign business partners:

“There is simply no better solution. I don't speak Chinese, I don’t speak Indian, I don't speak Japanese. [...] This morning I talked to a Japanese partner on the phone. It was awful English, but we sort of understood each other." (Ehrenreich, 2010, 420)

Although TechComp offers formal language training through its HR department, the managers overwhelmingly stated that they preferred "learning by doing", i.e. their necessary BELF skills were generally developed through exposure and interaction, or, as they put it, through "mutual engagement with international colleagues and business partners." $(2010,419)$ Interestingly, no one seemed to be too concerned with "correctness". While it is important that employees possess an accurate knowledge of technical and business vocabulary, the overall notion of confirming with the rules of Standard English is considered a "fairly irrelevant topic" and "only a matter of prestige." $(2010,418)$ Manager "B", for instance, points out that ELF's main function is transmitting information effectively and across language boundaries:

"I must say I'm confronted with so many levels of correctness that I don't actually care whether something is correct or incorrect. As long as the meaning is not distorted." (Ehrenreich, 2010, 418)

These pragmatic attitudes concerning "correct English" might sound alarming to English instructors, but they seem to correspond entirely to the arguments that scholars and proponents of ELF/BELF have put forth. To quote Seidlhofer again:

"ELF speakers are not primarily concerned with emulating the way native speakers use their mother tongue within their own communities, nor with socio-psychological and ideological issues. Instead, the central concerns for this domain are efficiency, relevance, and economy. $(2000,57)$

Even so, the managers in Ehrenreich's study mentioned that dealing with different proficiency levels of English on a daily basis was tiresome, time consuming, and prone to "a substantial loss of detail." $(2010,421)$. Nonetheless, none of the interviewees had ever lobbied to consider their own mother tongue German, after all the native language of more than 100 million speakers, to be the lingua franca. While German is still spoken extensively at TechComp in situations that involve native speakers only, it is considered unsuitable and "simply not an option" $(2010,424)$ for international interactions, or, as manager "C" put it succinctly: "German is out of the question." (Ehrenreich, 2010, 424)

The Rakuten and TechComp examples show a rather soft approach to implementing ELF/BELF.

However, such approaches are not always the case in Europe. A professional group that is affected on a large scale and even across-the-board by ELF/BELF is academics. More and more universities in continental Europe are issuing "top-down" English-only mandates to their faculty, which primarily means that professors and researchers have to teach their courses in English regardless of the university's location and that they have to publish their research in English. These kind of official language policies are often the result of self-perceived crises by universities who fear that they will be no longer relevant if they do not switch to BELF, and sometimes they are brought about by requests from the student body who demand that they be taught in English to improve their future job prospects. This is particularly the case at the University of Hamburg, Germany, whose administration calls its new language policies "internationalization efforts" (Gonzalez, 2017, 49-62). Even more so than at Rakuten, the faculty at the University of Hamburg have no choice but to use English for their professions. Otherwise, as the Times Higher Education reported, "they [faculty] can forget tenure unless they publish in English." (Note 7) According to Gonzalez $(2017,57)$, English skills are now equally or even more important in hiring faculty than expertise. One professor from the university reported: 
"If you applied for a faculty position right now, you have to give at least one presentation in English and then that discussion is in English; but 10 years ago that was not common." (Gonzalez, 2017, 57)

Although one might assume that switching to English should not present a significant problem for academics, writing academic articles in a language other than one's native language can be extremely challenging. Most of the highest ranked professional journals, however, are in English, and therefore make it mandatory for faculty in Germany and elsewhere to have an excellent command of the language. Unlike TechComp, the faculty at the University of Hamburg expressed resistance to the shift and remains "deeply ambivalent" about teaching and publishing in English, with one even threatening to sue the university rather than switch languages. (Gonzalez, 2017, 53)

The final European case study surveyed five companies from Finland that are globally operating and which either adopted English as an internal lingua franca or used BELF extensively in their daily interactions with business partners. The authors studied the Finnish users' perceptions of BELF, and, very similar to the German study, the main takeaway was a very pragmatic attitude toward using English on the job:

"The use of English in today's global business environment is "simply work". This is the main message we learned from our informants, whose work involves regular international interaction. For the generation that has entered the labour market since the 1990s, English is and always has been an integral part of work." (Kankaaranta \& Louhiala-Salminen, 2009, 207)

In addition, the Finnish participants expressed little concern for "correctness", but instead, like their counterparts at TechComp, were more concerned with efficiency:

"They [the BELF users] considered knowledge of grammar clearly less important than knowledge of particular genres of their own business area." ((Kankaaranta \& Louhiala-Salminen, 2009, 207)

One of the most significant and interesting points of the TechComp study and the Finnish companies was how the German and Finnish participants evaluated interactions with business partners who are native English speakers. The German managers from TechComp had a decidedly negative view of native speaker interlocutors. They commented that "native speakers frequently use their native competence as an instrument of power." (Ehrenreich, 2010, 422). Furthermore, native English speakers were described as "fairly inconsiderate interlocutors with apparently little accommodation skills." (Ehrenreich, 2010, 422). Manager "C" comments why interactions with native speakers are considered particularly challenging:

"Of course, you can ask them to talk less and to slow down. And all they do is raise their voices. It [accommodating] seems to be difficult for them. And you can't really attack him [the native speaker] because there is always this residual risk, did I just get him wrong, or is he actually talking rubbish?" (Ehrenreich, 2010, 422)

The Finnish participants had a similar view of their interactions with native English speakers:

"Communication with NSs [Native Speakers] was considered unequal and at times uncomfortable because NSs were able to gain the upper hand by exploiting their mother tongue to the full, whereas in NNS [NonNative Speakers] communication everybody was on the same footing." (Kankaaranta \& LouhialaSalminen, 2009, 207)

Nonetheless, the study's authors report that some Finnish participants had a more positive opinion of their native speaker interlocutors and "regarded them as teachers" ((Kankaaranta \& Louhiala-Salminen, 2009, 207)

This last point leads us to a crucial aspect related to the general ELF/BELF debate, namely the attitudes of native English speakers toward learning the language and culture of their business partners.

\section{Methodology III: Opinions from English-speaking Countries}

It has long been a rather contentious issue whether native speakers of English should be required to master a foreign language given that so many people in the world are speaking English or learning it. It should be noted that opposing the idea (if not the value) of foreign language learning in general is a somewhat rare occurrence in the world and sometimes associated with nationalist-authoritarian regimes. Presently, in the English-speaking world such opposition is mostly restricted to ideological hardliners in just a handful of nations, among them the United States, the United Kingdom, and, to a lesser degree, Australia, i.e. very powerful countries with very advanced economies. Ideological issues, however, are usually not the main reason for a certain reluctance among native speakers of English to take up a foreign language. David Thomas, for instance, a columnist for the British newspaper The Daily Mail, believes that it is simply not a necessity because so many "foreigners" are learning English. In an op-ed Thomas wrote: 
"I think that those pupils who don't learn other languages are making an entirely sensible decision. Learning foreign languages is a pleasant form of intellectual self-improvement: a genteel indulgence like learning to embroider or play the violin. [...] But there is absolutely no need to learn any one particular language unless you've got a specific professional use for it. [...] All those foreigners who are so admirably learning another language are learning the one we already know. So our school pupils don't need to learn any foreign tongues." (The Daily Mail, 23 January 2012)

This kind of criticism is sometimes echoed by American college students, who often have to study a foreign language for several semesters in order to satisfy their colleges' foreign language requirements. Mark Murphy, a former Economics and Finance student at the University of Wisconsin (United States), wrote in the university's student newspaper:

"As more and more individuals learn English, the practical value of American students learning other languages decreases. The practice truly amounts to little more than a "kind gesture". [...] Across the board, foreign language requirements misdirect resources that could certainly be invested in more valuable endeavors." (The Badger Herald, 30 January 2006)

Similarly, Blake Hounshell, a managing editor at Foreign Policy, a U.S. publication that focuses on global affairs, and domestic and international policy, thinks that it is essentially unnecessary for Americans to study foreign languages:

“Most Americans don't really need to learn a foreign language: Many foreigners speak English, and the amount of bilingual jobs available is relatively small. It's a nice skill to have, but acquiring working-level fluency in a second or third language is expensive and time consuming, and often the potential payoff isn't worth it. My seven years of French has never been very useful, frankly, and I might have been better served learning more about microbiology or fluid dynamics." (Foreign Policy, 9 July 2008)

Such arguments sound dismissive and flippant to citizens of other nations, especially if they are bilingual or trying to learn English. However, these arguments are frequently the result of deep-seated frustrations and are centered on self-perceived notions that "they all speak better English than I can speak their language." It would go beyond the frame of this paper to find out if this is indeed the case. Although it is circular reasoning, it could be argued that such sentiments would not arise if the U.S. and the UK had more rigid standards for foreign language learning.

The arguments by Murphy and Hounshell speak to a worrying new trend in the United States, namely weighing whether learning a foreign language "pays off." This sort of materialistic stance views foreign language learning primarily as a commodity that has no intrinsic but only economic value. (Note 8) It is, of course, obvious that Rakuten, TechComp, and the Finnish companies discussed earlier were all operating in the same manner, i.e. they implemented BELF in their respective companies to increase the bottom line. The difference is that the Japanese, Germans, and Finns believed in the economic value of mastering English, while many American economists, academics, and increasingly U.S. college students now believe that learning foreign languages does not even yield any economic value (i.e. a higher paycheck).

Crystal mentions that "the need for a global language is particularly appreciated by the international academic and business communities." (2013, 13) More precisely, though, it is appreciated by the American academic and business community. Lawrence Summers, for example, a U.S. economist with an impressive résumé (Secretary of the Treasury under U.S. President Bill Clinton, President of Harvard University), wrote in a rather famous op-ed in the New York Times that an investment in learning to speak a foreign language is not worthwhile:

"The world is much more open, and events abroad affect the lives of Americans more than before. [...] It seems logical that more in the way of language study be expected of students. I am not so sure. English's emergence as the global language [...] makes it less clear that the substantial investment necessary to speak a foreign language is worthwhile." (New York Times, 20 January 2012)

Some of the most controversial arguments in this debate are provided by Bryan Caplan, Professor of Economics at George Mason University (Virginia, United States) and self-proclaimed economic libertarian:

"Lots of stuff that sounds good isn't worth doing. "Learning a foreign language" sounds noble, but so does "climbing Mount Everest." The wise calmly weigh costs and benefits instead of being carried away by words. Any honest scale will tell you that the costs of foreign language instruction dwarf the benefits. [...] The world usually has what economists call "diminishing return": you can improve outcomes by spending more money, but the more you spend, the less efficacious each dollar becomes." (Library of Economics and Liberty, 10 August 2012) 
In fact, Caplan manages to outdo all other opponents of foreign language requirements in the United States by claiming that English is superior to other languages.

"People around the world strive to learn English. Why? Because English fluency helps them get good jobs, meet interesting people, and enjoy culture. Pretty obvious, right? We [Americans] don't learn foreign languages because foreign languages rarely help $u s$ get good jobs, meet interesting people or enjoy culture. [...] And if Americans do decide to sample other pools, we can literally travel the world without needing to learn a word of another language." (Library of Economics and Liberty, 10 August 2012)

An obvious question regarding this comment is whether Italians, French, Germans, Russians, Chinese, Arabs, Mexicans, or Japanese really need to learn English in order to "enjoy culture." It must be pointed out that numerous studies within the Anglo-American context have concluded the opposite, i.e. mastering a foreign language usually "pays off" in the long run and is frequently considered a career-booster. (Note 9) MIT (Massachusetts Institute of Technology, United States) economist Albert Saiz, however, argues that bilingualism does not really pay off in the American job market. In a much-cited study, bursting with abstract mathematical formulas and thus providing a good example how foreign language learning is reduced to a commodity in the U.S., Saiz points out that having mastered a foreign language offers only minimal economic value. Similar to Caplan, Saiz thinks that the problem in the U.S. is diminishing return:

"Our estimates of the impact of bilingualism on earnings are relatively small (2\%-3\%) and compare unfavorably with recent estimates on the returns to one extra year of general schooling (8\%-14\%), which may help explain current second-language investment decisions of monolingual English-speakers in the United States." $(2005,535)$

To be fair, some of the opinions cited in this section must be understood within the context of tuition fees at U.S. universities, which have increased by an incredible one thousand and one hundred percent since 1978. (Note 10) The U.S. College Board reported that the average cost of tuition and fees at American state universities in the 2017-2018 school year runs to roughly $\$ 10,000$. The Board estimates that room, board, transportation, and books cost an additional $\$ 12,000$, and concludes that a "moderate budget" for a U.S. state university for the 2017-2018 academic year averages $\$ 25,290$. (Note 11) Many students are therefore forced to take out substantial loans in order to finance their studies, which they have to repay after graduation. In fact, the "student debt crisis" in the United States is such a controversial issue that many politicians, among them former president Obama and current president Trump, have sharply criticized universities for their ever-increasing tuition costs. The Pew Research Center, a U.S. think tank, estimated that Americans owed more than $\$ 1.3$ trillion on student loans by the middle of 2017, and that approximately $37 \%$ of Americans between the ages of eighteen and twenty-nine have outstanding student loans. (Note 12) Viewed in this light, it becomes quite clear that the commodification of foreign language learning is just a small part in the overall commodification of a college education in the United States.

Finally, and rather paradoxically, the emergence and diffusion of ELF and BELF does not necessarily seem to elicit a great deal of appreciation from Anglo-American linguists. David Graddol, for instance, a British linguist, sees the global status of English undermined by these new developments. In a report (2006) for the British Council, an organization that promotes English learning around the world, Graddol wrote:

"It [ELF and BELF] is a new phenomenon, and if it represents any kind of triumph it is probably not a cause of celebration for native speakers." $(2006,64)$

While this reference to ELF/BELF's lack of conformity to the rules of Standard English disputes Seidlhofer's et al. arguments, it could be considered, at least at first glance, a valid concern in the eyes of English speaking academics. It also hints at fears that over time ELF or BELF will transform into independent languages (a sort of "Globish"), which then must be learned and studied by native speakers of English. Mufwene, a U.S. linguist, also criticizes the lack of concern for grammatical correctness that many ELF/BELF speakers seem to exhibit:

"I wonder who learns another group's language not caring at all about being understood (and being accepted) by the native-speaking community." $(2012,368)$

Such evaluations, however, must sound discouraging and almost tone-deaf to the efforts of millions of people around the world, who are learning English to improve their professional lives. (Note 13)Mufwene also does not seem to consider the main function of ELF and especially BELF, which is not to interact with native speakers of English but to connect speakers of vastly different linguistic backgrounds.

It is perhaps not surprising that the global spread of English and particularly some of the above-mentioned sentiments - even though they might not be representative of the U.S. and the U.K. as a whole - are met with 
concern and even animosity by other nations, or that they engender cris de coeur of "linguistic imperialism" and other nefarious forms of imperialism.

\section{Voices of Resistance}

Although Great Britain still commands an impressive presence in the world, the days of the British Empire are long gone. Nowadays, it is the United States that is seen as the main force behind the global spread of English. Inevitably, the modern spread of English is associated by many people with globalization, which in its turn is often associated with "Americanization". It is not the intention of this paper, however, to discuss the pros and cons of globalization, or to analyze how much the global spread of English is driven by globalization or "Americanization". (Note 14) It should be pointed out, though, that the United States itself is the product of $17^{\text {th }}$ - and $18^{\text {th }}$ - century globalization as various European countries expanded to colonize other continents. Furthermore, the results of recent elections or referendums in the U.S., the UK, Germany, Austria, and other European countries strongly suggest that many citizens in these countries, whose governments were among the first to propagate globalization, presently strongly question and even reject this idea.

This section, thus, considers the spread of English a fait accompli and instead examines some examples of opposition to it. The purpose of the Verein Deutsch Sprache, mentioned in the introduction, is not to publicly shame people like Günther Oettinger; rather it owes its existence to profound concerns that English is encroaching on the German language and culture, e.g. the significant increase of Anglicisms in recent years and their transmission into German. The society is wondering, for example, why many protestant churches in Germany now call their free WLAN spaces God spots, or why these churches try to win new members in Germany with slogans like Moments of Blessing; or why Karstadt, a leading German department store, calls its children apparel kidswear and offers Midseason-Sales; or why museums in Frankfurt try to attract more young visitors by having family days. Such examples may sound trivial, nonetheless they can feel thoroughly irritating to native speakers of German, particularly since the German language already has words for these expressions. The ubiquity of English loan words often leads to a sense of alienation in one's own country and culture. Similar to Germany, there are concerns in Japan that the spread of English will cause irrevocable changes to Japanese culture and society:

"When one looks at the rampant use of English loan words in Japanese, it is almost impossible to live in Japan without knowing English. This process of internationalization has proceeded at the expense of a loss of Japanese culture and identity among young people. Japan can be said to be witnessing the marginalization of Japanese culture in the name of globalization." (Ota, 1, 2001)

The worries regarding national and cultural identity, and traditional ways of life are even more pronounced in countries that are not traditional allies of the United States but have strained relations with them, for example in China:

"English as a dominant language worldwide is forcing an unfamiliar pedagogical and social culture on to its learners, socio-psychologically, linguistically and politically putting them in danger of losing their first languages, cultures and identities, and contributing to the devaluation of the local knowledge and cultures in China. [...] The global spread of English is not only a product of colonialism, but also the most potent instrument of cultural control." (Guo \& Beckett, 2007, 119)

Other scholars see the new lingua franca not only as a threat to national identities but are concerned that the world's elemental linguistic and cultural balance will eventually be affected. Garfolo and L'Huillier (2017), for instance, believe that the global spread of English will lead to "disempowering of the locals [...] and homogenization of culture, identity and cultural experience." $(2017,211)$. Researchers, who view ELF/BELF as a new form of imperialism are most of all concerned that the general public is too uncritical and too enamored with English to notice potential dangers:

"The 'English-speaking-world' is saturated with uncritical, hegemonic views of the global appropriacy of English and the benefits that accrue from using the language." (Phillipson \& Skutnabb-Kangas, 1997, 39)

Since the spread of English is a global phenomenon, it is unlikely that there is presently a country not grappling, in one way or another, with questions of national identity and culture. However, this certainly does not mean that every German, Japanese, or Chinese is opposed to the spread of English, precisely because it is a universal phenomenon. In addition, it is a very common outcome of language learning that those who master a foreign language enjoy using it. While the United States must be considered an initial driving force behind the recent, more modern global spread of English, the examples from Germany and Japan (but maybe not China) demonstrate how little the U.S. and its citizens actually have to do with the present "Englishnization" in these countries. It rather seems to be the case that English has taken on a life of its own. There are, for example, dozens of hybrid or 
pseudo-English words in both languages (also called "Denglisch" in Germany, a mixture of Deutsch and Englisch) that often make little to no sense to native speakers of English. Such neologisms are, however, not the product of undercover American agents whose mission it is to infiltrate and corrupt the German and Japanese languages, but rather of German and Japanese media outlets, fashion designers, advertising agencies, and hip entrepreneurs, who are the real agents of these language changes. (Note 15)

Concerns about national identity and the purity of native languages are real worries in Japan, Germany, and China. There are tens of millions of native Japanese and German speakers and more than a billion native Chinese speakers. Only time will tell if the three languages are able to absorb these changes without much damage, or if the growing influence of English is really going to permanently alter them and their cultures. The situation is very different, however, for those languages that do not have millions of native speakers.

\section{The Impact of English on Minority and Endangered Languages}

In 2000, Chief Mary Smith Jones, the last speaker of Eyak, a Native American language once widely spoken in Alaska, was quoted by Nettle and Romaine about the imminent extinction of her native language:

"I don't know why it's me, why I'm the one. I tell you, it hurts, it really hurts." (Nettle \& Romaine, 2000, 14)

In 2008, Chief Smith Jones passed away, and with her death Eyak became extinct. In 1996, a Native American called Red Thunder Cloud died in South Carolina. He was the last living speaker of Catawba, the ancient language of his people. In 1992, a Turkish farmer named Tefvik Esenc, died in his home village. He was the last living speaker of Ubykh, a language once spoken in the northwestern Caucasus. The inscription of his gravestone reads:

"This is the grave of Tefvik Esenc. He was the last person able to speak the language they called Ubykh." (Nettle \& Romaine, 2000, 18)

This is not a list of some isolated and agonizing examples of language deaths. In fact, it could be continued indefinitely. Since the $20^{\text {th }}$ century, the world has been experiencing an unprecedented dying off of languages, which has been extensively documented and analyzed by scholars (Krauss, 1992; Crystal, 2000; Nettle \& Romaine, 2000; Dalby, 2003; Harrison, 2007). It would go beyond the scope of this paper to detail this colossal problem. Suffice it here to enumerate some facts:

- According to Ethnologue, the world's most authoritative, encyclopedic reference work for languages, there are 7,097 languages spoken in the world in 2018. (Note 16) The number, though, is constantly in flux, and their distribution is very uneven as well. $81 \%$ of the world's languages are spoken in Africa, Asia, and the Pacific. By comparison, all of Europe and the Middle East together have only two hundred and seventy five, or ca. $4 \%$ of the world's languages.

- A mere twenty-three languages account for more than half of the world's population (currently ca. 7.6 billion people). This has left minority languages and lesser known languages in acute danger of extinction within the next decades. Researchers' predictions on the number of languages in danger of extinction vary: While Nettle and Romaine (2000:7) estimate that about half of the world's languages will die out in the $21^{\text {st }}$ century, Crystal (2000: 15$)$ believes that around 4,000 languages are endangered. According to Dalby (2003: ix), this figure translates to one language death every two weeks in this century.

Some scholars (e.g. Phillipson, 1992) believe that the global spread of English is, at least to some extent, responsible for the world's language crisis and warn of "linguistic imperialism" (Phillipson, 1992) or term English a "killer language" (Eckert et al., 2004). Krauss (1992) points out that native speakers of English have wreaked inconceivable destruction (language murder or linguicide) among the indigenous languages and their speakers in the two continents they have settled, North America and Australia:

"English-language dominance in the 'English-speaking world' has achieved and continues to achieve the highest-documented rate of destruction [of indigenous languages], approaching now $90 \%$." $(1992,5)$

One could ask whether ELF/BELF, whose conception and spread is mostly benign, unintentionally contributes to the rapid dying off of languages. Although they are confronted with the influence and dominance of English, it is more than doubtful that German, Japanese, and Chinese will become extinct or replaced by English. However, the popularity of ELF/BELF does become a serious problem if it is not merely used for professional or communicative purposes but rather turns into a way of life, i.e. when speakers of minority or endangered languages abandon their own languages wholesale in favor of English. (Note 17) It is important to consider in this context Harrison's observation (2007) that expressions, such as "to become extinct" or "language shift" are actually misnomers: 
"Languages do not literally 'die' or go 'extinct', since they are not living organisms. Rather, they are crowded out by bigger languages. Small tongues get abandoned by their speakers, who stop using them in favor of a more dominant, more prestigious tongue." $(2007,5)$

Various scholars (Nettle \& Romaine, 2000; Rapatahana \& Bunce, 2012) have demonstrated that such a scenario was and is indeed often the case among smaller languages in Africa and the Pacific, and that the "more dominant, more prestigious tongue" in question is usually English. It needs to be pointed out, though, that there is a lack of empirical studies to prove these shifts of language use and language loyalty. Furthermore, since BELF is a relatively new phenomenon, it is unclear what exactly its role is in this process. Large scale studies would be needed in order to ascertain whether the emersion and spread of ELF/BELF is really a contributing factor to the world's vanishing voices.

It is interesting but perhaps not surprising that scholars who categorically deny a link between the global spread of English and the world's language crisis are predominantly from the United States (e.g. Mufwene 2002, 2012; Brutt-Griffler, 2005). Their main argument is the above-mentioned lack of empirical studies. In addition, both point out that brute force, which was employed in the colonial past, is usually no longer a factor, and that people choose and change languages or abandon them of their own free will. This argument is supported by several researchers and writers from former British colonies. Bisong (1995), a scholar from Nigeria, argues that the dominance of English in Nigeria has not caused Nigerian culture to be undervalued or marginalized as Nigerians are sophisticated enough to know what to take from Anglo-European culture and what not. Several linguists (e.g. Phillipson, 1992) believe that the only way to counter English "linguistic imperialism" is to promote indigenous languages. Bisong cautions that this belief is simplistic and "pointless" $(1995,126)$ and notes that such an undertaking would create its own set of new problems:

"The promotion of the once native language may not be without its own oppressive strategies." $(1995,126)$

Bisong also makes it clear that he does not consider the English language to be a threat to the indigenous languages in his homeland:

"Although English is the official language of Nigeria it has not succeeded in displacing or replacing any of the indigenous languages. It performs a useful function in a multilingual society. [...] Nigerians are sophisticated enough to know what is in their interest $[\ldots]$ and to operate with two or more linguistic codes." $(1995,131)$

The Bangladeshi scholar Fakrul Alam also seems unperturbed by the dominance of English in his home country and points out that his parents sent him to an English school "not just because the best jobs would go to people who were the most fluent in English, but also because I would eventually pick up Bengali in the world I lived in." (2007, 373). Bisong's arguments, in particular, hint at the flip side of linguistic activism in that its proponents can appear patronizing towards endangered languages and their speakers by displaying a "we-know-what's-best-foryou" attitude.

Nonetheless, scholars who contest an interconnection between the global spread of English and the disappearance of indigenous languages sometimes exhibit a similar condescending attitude. Brutt-Griffler, for instance, seems to refute the fact that Africa is home to many indigenous languages and refers to them as "so-called indigenous languages" (the word indigenous itself appears in quotation marks throughout her article). Mufwene (2012) manages to eclipse such sentiments by declaring rather unapologetically:

"I accept ELF as a fact, a beneficial outcome from the British imperial expansion and the emergence of American hegemony since the early $20^{\text {th }}$ century." $(2012,366)$

\section{Discussion and Conclusion}

This paper discussed the implementation of English as a Business Lingua Franca (BELF) by various businesses across different countries. Although BELF, by its very nature, comes with significant ramifications it was shown in this paper that most employees affected by it seem to consider it as a largely beneficial tool. This paper also noted that many employees make use of BELF in a very pragmatic manner and thus consider its impact as mostly non-invasive, although this was not corroborated by all case studies (e.g. Rakuten, University of Hamburg). Furthermore, this paper has shown that most users of BELF highlighted its communicative aspects and frequently viewed grammatical correctness as a peripheral aspect.

The case studies from Japan, Germany, and Finland on the one hand, and the debate over foreign language learning in the United States on the other hand represent two fundamentally different mindsets and approaches toward learning foreign languages. In all cases, mastering a foreign language is primarily seen as a commodity, i.e. as an economic gain, either to lift one's own economic situation or to boost the profit of a business or corporation. The 
difference is that the economic value associated with learning English is very high for non-native speakers of English, while the economic value for learning a language other than English seems to be nonessential and expendable for many native speakers of English. To a certain degree, this just reflects the reality of the world as it is. It is somewhat ironic that the reluctance and disinterest of American students to seriously study a foreign language is viewed as a national security crisis by the country's intelligence community. A panel of the United States' Senate, for instance, found that in 2017 only $28 \%$ of language jobs at the U.S. Defense Department were "filled with personnel at the required foreign-language proficiency level." (Note 18) The panel's report concluded that the United States' national security is compromised if important positions in intelligence services or government cannot be filled with persons who are fully proficient in certain foreign languages ("critical languages"). The panel also called for a greater commitment to foreign language instruction at all U.S. colleges and universities.

Yet another train of thought, which is quite trendy on the United States' West Coast, is that foreign language learning will become obsolete altogether in the future. Singularity University, for instance, a Silicon Valley think tank, predicts that technology will replace learning foreign languages. David J. Hill, the editor-in-chief of the think tanks' website, believes that a "universal translator similar to a mathematical calculator" will be the tool of the future and thus make learning a foreign language superfluous:

"There's nothing wrong with learning a language for fun, but the days of believing that you have to know a second language are over." (Singularity Hub, 24 July, 2012)

This paper argues that learning a foreign language can be a significant factor for improving career opportunities, including for native speakers of English. However, communicating in different languages should not be exclusively seen as an economic commodity. Even though the need for a lingua franca might be greater than ever, learning a foreign language and its attendant culture and worldview is still the best way to become an open-minded, understanding individual. As the world is moving closer together it is important that tomorrow's leaders, CEOs, and innovators will be global citizens. English alone is not enough. Monolingualism can come across as a sign of inflexibility, insensitivity, or arrogance. At the very least, learning a foreign language makes people more aware and perceptive of their own language; or as the great German poet Johann Wolfgang von Goethe once said:

Wer fremde Sprachen nicht kennt, weiß nichts von seiner eigenen.

Those who do not know foreign languages, know nothing of their own.

\section{References}

Alam, F. (2007). Imperial Entanglements and Literature in English. Dhaka, Bangladesh: The University Press Limited. https://doi.org/10.9783/9780812208511.13

Bisong, J. (1995). Language choice and cultural imperialism: A Nigerian perspective. ELT Journal, 49(2), 122132. https://doi.org/10.1093/elt/49.2.122

Bragg, M. (2011). The Adventure of English: The Biography of a Language. New York: Arcade Publishing.

Brutt-Griffler, J. (2005). "Globalisation" and Applied Linguistics: post-imperial questions of identity and the construction of applied linguistics discourse. International Journal of Applied Linguistics, 15(1), 113-115. https://doi.org/10.1111/j.1473-4192.2005.0083a.x

Caplan, B. (2012, August 10). The numbers speak: Foreign language requirements are a waste of time and money. Library of Economics and Liberty. Retrieved from http://econlog.econlib.org/archives/2012/08/the_marginal_pr.html

Crystal, D. (2000). Language Death. Cambridge: Cambridge University Press. https://doi.org/10.1017/cbo9781139871549

Crystal, D. (2003). English as a Global Language, $2^{\text {nd }}$ Ed. Cambridge: Cambridge University Press. https://doi.org/10.1017/cbo9780511486999

Dalby, A. (2003). Language in danger. New York: Columbia University Press.

Eckert, T., Johann, A., Känzig, A., Küng, M., Müller, B., Schwald, C., \& Walder, L. (2004). Is English a Killer Language? The Globalisation of a Code. eHistLing, 1(1), 106-118.

Ehrenreich, S. (2010). English as a Business Lingua Franca in a German multinational corporation. Journal of Business Communication, 47(4), 408-431. https://doi10.1177/0021943610377303

Friedman, T. L. (2000). The Lexus and the Olive Tree. New York: Anchor Books. 
Garfolo, B. T., \& L'Huillier, B. (2017). Ethics, Globalization, and the Role Educators Play. Athens Journal of Education, 4(3), 211-222.

Gonzalez, R. G. (2017). Internationalization at a German University: The purpose and paradoxes of English Language. The International Education Journal: Comparative Perspectives, 16(2), 49-62.

Graddol, D. (2006). English Next: Why Global English might mean the end of "English as a foreign language." The British Council: The English Company (UK) Ltd.

Guo, Y., \& Beckett, G. (2007). The hegemony of English as a global language: Reclaiming local knowledge and culture in China. Convergence, 40(1-2), 117-132.

Harrison, K. D. (2007). When Languages die. Oxford: Oxford University Press. https://doi.org/10.1093/acprof:oso/9780195181920.001.0001

Hazlehurst, J. (2010, August 27). Learning a foreign language: now you're talking. The Guardian.

Heinrich, P. (2012). The Making of Monolingual Japan: Language Ideology and Japanese Modernity. Bristol: Multilingual Matters.

Hill, D. J. (2012, July 24). Will it matter if we speak different languages in the future? Singularity Hub. Retrieved from https://singularityhub.com/2012/07/24/will-it-matter-if-we-speak-different-languages-in-thefuture/\#sm.0001wa46mes1se13101pukt6adhzg

Hounshell, B. (2008, July 9). The case against foreign language study. Foreign Policy. Retrieved from http://foreignpolicy.com/2008/07/09/the-case-against-foreign-language-study/

Jenkins, J. (2007). English as a lingua franca: Attitude and identity. Oxford: Oxford University Press.

Kankaaranta, A., \& Louhiala-Salminen, L. (2009). "English? - Oh, it's just work!”: A study of BELF users' perceptions. English for Specific Purposes, 29, 204-209. https://doi.org/10.1016/j.esp.2009.06.004

Kraus, M. (1992). The world's languages in crisis. Language 68 (1), 4-10. https://doi.org/10.1353/lan.1992.0075

$\mathrm{Ku}, \mathrm{H} .$, \& Zussman, A. (2010). Lingua franca: The role of English in international trade. Journal of Economic Behavior \& Organization, 75, 250-260. https://doi.org/10.1016/j.jebo.2010.03.013

Lohmann, J. (2011). Do language barriers affect trade? Economic Letters, 110, 159-162. https://doi.org/10.1016/j.econlet.2010.10.023

Louhiala-Salminen, L., \& Kankaaranta, A. (2012). Language as an issue in international internal communication: English or local language? If English, what English? Public Relations Review, 38, 262-269. https://doi.org/10.1016/j.pubrev.2011.12.021

McCrum, R., Macneil, R., \& Cran, W. (2002). The Story of English: Third Revised Edition. London: Penguin Books.

Mufwene, S. (2012). English as a lingua franca: Myths and facts. Journal of English as a Lingua Franca, 1-2, 365-370. https://doi.org/10.1515/jelf-2012-0023

Murphy, M. (2006, January 30). Foreign language requirement unnecessary in college. The Badger Herald. Retrieved from https://badgerherald.com/opinion/2006/01/30/foreign-language-req/

Neeley, T. (2012). Global business speaks English. Harvard Business Review, May Issue 2012, 53-63.

Neeley, T. (2017). The language of global success. Princeton: Princeton University Press.

Nettle, D., \& Romaine, S. (2000). Vanishing Voices: The Extinction of the World's Languages. Oxford: Oxford University Press.

Ota, N. (2001). Impact of globalization on Japanese language and culture. Toronto: York University.

Phillipson, R. (1992). Linguistic imperialism. Oxford: Oxford University Press.

Phillipson, R., \& Skutnabb-Kangas (1997). Linguistic human rights and English in Europe. World Englishes, 16(1), 27-43. https://doi/10.1111.1467-971X.0044

Rapatahana, V., \& Bunce, P. (Eds. 2012). English Language as Hydra: Its Impacts on Non-English Language Cultures. Bristol: Multilingual Matters. https://doi.org/10.21832/9781847697516

Rashid, B. (2017, June 12). Three corporate benefits of learning a foreign language and why you should care. Forbes.

Reaume, A. (2014, November 8). Will tuition ever stop increasing? USA Today. 
Rubdy, R., \& Tan, P. (2008). Language as Commodity: Global Structures, Local Marketplaces. London: Continuum International Publishing Group.

Saiz, A., \& Zoido. E. (2005). Listening to what the world says: Bilingualism and earnings in the United States. The Review of Economics and Statistics, 87(3), 523-538. https://doi.org/10.1162/0034653054638256

Seidlhofer, B. (2000). Mind the gap: English as a mother tongue vs. English as a lingua franca. Vienna English Working Papers, 9(1), 51-69.

Seidlhofer, B. (2001). Closing a conceptual gap: the case for a description of English as a lingua franca. International Journal of Applied Linguistics, 11(2), 133-158. https://doi.org/10.1111/1473-4192.00011

Seidlhofer, B. (2011). Understanding English as a Lingua Franca: A Complete Introduction to the Theoretical Nature and Practical Implications of English Used as a Lingua Franca. Oxford: Oxford University Press.

Smokotin, V., Alekseyenko, A. S., \& Petrova, G. I. (2014). The Phenomenon of Linguistic Globalization: English as the Global Lingua Franca (EGLF). Procedia: Social and Behavioral Sciences, 154, 509-513. https://doi.org/10.1016/j.sbspro.2014.10.177

Summers, L. H. (2012, January 20). What you (really) need to know. The New York Times.

Thomas, D. (2012, January 23). Why do the English need to speak a foreign language when foreigners all speak English? The Daily Mail.

Trudgill, P., \& Hannah, J. (2002). International English: A Guide to the Varieties of Standard English, $4^{\text {th }}$ Ed. London: Arnold.

United States Congress, United States Senate, Committee on Homeland Security. (2017). A national security crisis: Foreign language capabilities in the federal government. Retrieved from http://www.fdsys.gov.

\section{Websites}

"Rakuten forges ahead in English" (2015, March 23). Editorial, The Japan Times. Retrieved from https://www.japantimes.co.jp/opinion/2015/05/23/editorials/rakuten-forges-ahead-english/\#.WuNBwS74M8

"Sprachpanscher des Jahres - Verein Deutsche Sprache e.V." Retrieved from http://vds-ev.de/serviceview/sprachpanscher-des-jahres/

\section{Notes}

Note 1. Retrieved from http://vds-ev.de/allgemein/was-tun-wir-fuer-die-deutsche-sprache/

Note 2. For more information, see Guiso, Sapienza, Zingales (2009, 1095-1131).

Note 3. For more information, see Sanders, year, etc.

Note 4. It should be pointed out that Classical Greek was perhaps the only significant lingua franca that was spoken, learned, and imitated by non-native speakers because of its rich literature, culture, and sophistication.

Note 5. This is not to say that the United States does not use hard power, especially regarding the past five decades. However, the conflicts in which the United States is or were involved usually do not contribute to the spread of the English language. If anything, these conflicts actually produce resentment towards English.

Note 6. For more information, see Heinrich (2012).

Note 7. https://www.timeshighereducation.com/news/study-finds-european-resistance-to-teaching-english

29 July 2017. According to the report, one faculty members described the situation as "Publish in English or perish in German."

Note 8. For more information, see Rubdy \& Tan (2008).

Note 9. Some examples: "Learning a foreign language: now you're talking” (The Guardian, 27 August 2010); "Three corporate benefits of learning a foreign language and why you should care" (Forbes, 12 June 2017).

Note $10 . \quad$ Source: $\quad$ USA Today (2014). Retrieved from https://www.usatoday.com/story/money/personalfinance/2014/11/08/credit-dotcom-tuition/18417721/

Note 11. Source: College Data (2018). Retrieved from https://www.collegedata.com/cs/content/content_payarticle_tmpl.jhtml?articleId=10064 
Tuition fees at private universities in the United States are much higher and can run to $\$ 50,000$ to $\$ 60,000$ per academic year.

Note 12. Source: Pew Research Center. Retrieved from http://www.pewresearch.org/fact-tank/2017/08/24/5-factsabout-student-loans/

Note 13. There is also an old adage that linguists describe languages and not prescribe them.

Note 14. For more information on the pros and cons of globalization, see Friedman, 2000.

Note 15. A fact that the Verein Deutsche Sprache definitely understands.

Note 16. Source: Ethnologue. Retrieved from https://www.ethnologue.com/guides/how-many-languages

Note 17. The Ethnologue points out that roughly one-third of all languages have less than 1,000 speakers remaining. Source: https://www.ethnologue.com/guides/how-many-languages

Note 18. For detailed information, see "A national security crisis: foreign language capabilities in the federal government".

\section{Copyrights}

Copyright for this article is retained by the author(s), with first publication rights granted to the journal.

This is an open-access article distributed under the terms and conditions of the Creative Commons Attribution license (http://creativecommons.org/licenses/by/4.0/). 